\title{
Based on Gravity Method of Logistics Distribution Center Location Strategy Research
}

\author{
Zhao XueYing \\ College of Electronic and Information Engineering \\ Shengyang Aerospace University \\ Shengyang China
}

\begin{abstract}
In the traditional logistics center location model, mostly assumptions that are involved in the logistics system of inventory costs, transportation costs, demand, transportation time, and other key factors as the known constant, and then based on the required one or more logistics center. But in practice, some influence logistics center location factor is not certain, such as geography, economic factors, environmental factors, the transportation time by traffic influence to wait, thus formed the location of the logistics center uncertain environment. In the complex logistics system design, should these uncertain factors into consideration. This paper introduces the logistics center and outlets of the layout of the relevant concepts; This paper illustrates the theory of gravity method under the guide of the logistics center location method, which tells the story of the development of the method of gravity, advantage, the basic principle and application of the analytic hierarchy process (ahp) basic steps; Focuses on the actual site selection factors, the model is built and the solving algorithm and will last a gravity method is applied to an example in, find out the best logistics center address is effectively, accord with the actual situation.
\end{abstract}

Keywords-Logistics center; Location; Gravity method; Logistics planning

\section{RESEARCH STATUS OF LOGISTICS DISTRIBUTION CENTER LOCATION PROBLEMS AT HOME AND ABROAD}

\section{A. Research status of logistics distribution center location at abroad}

The foreign study of logistics center location problems has a history of more than several dozen years, and remarkable achievements have been made both in the aspect of theory and practice on all types of logistics center location selection problems; many feasible models and methods have been formed. Sum up, the logistics center location can be divided into three categories:

The application of continuous location;

The application of discrete location;

The application of Delphi expert consultation method location.

So, the above methods are often effective for limited optional location, but enough basic data needed in the research of logistics center location taking the whole city system as the research object, in which quantitative analysis is supplemented, otherwise it's lack of convincing. Research status of logistics distribution center location at home
Domestic logistics center location research starts relatively late, only more than 10 years of history; many scholars have carried on the thorough research on it, and made achievements in theory and in practice. The domestic study on the third type of logistics center location method is relative less, mainly the in-depth analysis on site selection influencing factors in the planning and layout of logistics parks.

\section{OVERVIEW OF LOGISTICS DISTRIBUTION CENTER LOCATION}

\section{A. Basic concept of logistics center}

"Logistics Center" is a new concept mainly used in academic and corporate circles in Asian countries and regions, such as China, Taiwan, Japan, etc. The concept of Logistics Center has broad sense and narrow sense. The broad sense of Logistics Center includes harbor, freight station, transportation warehouse operators, public circulation commodity distribution Center, logistics facilities owned by the enterprise; the narrow sense focuses on the management efficiency of logistics and behavior.

\section{B. Principle of logistics distribution center location}

Logistics center location process should comply with adaptive principle, harmony principle, economy principle and strategic principles.

\section{Main methods and types of logistics distribution center location}

\section{1) Types of location}

In recent years, with the rapid development of the location theory, various kinds of site selection emerge in endlessly. Especially the development and application of computer technology, promotes the development of logistics system location theory, and provides a powerful tool for analyzing the feasibility of different scheme. But the present theoretical method of location in general has the following categories:

\section{a) Operation method}

Operation method is the method of using mathematical model for logistics network distribution.

\section{b) Expert advice method}

Expert advice method is to ask for information from experts, to consider the social environment and the objective background of location object using expert knowledge and experience, and to visually seek its 
characteristic and law of development of location objects and make the choice.

\section{c) Simulation method}

Simulation method is to denote practical problems via mathematics method and the logical relationship and then determine the best layout scheme through simulation calculation and logic. The advantage of this method is simple, and the disadvantage is that choosing this method for location selection, analysts must provide scheduled various network groups for analysis and evaluation, and find the best combination.

2) Typical methods for logistics center location decision

\section{a) single-point logistics center location method}

Single-point branch location refers to the problems of single logistics facilities location in the area of the planning, which mainly includes the following ways:

\section{b) Cross median method}

Establishing logistics facilities in the city is unlikely to choose without restriction, and it's possible to choose one location along the overlapping streets. Cross median model is a single facility location method using urban roads network as the location scope.

\section{c) Factor-rating method}

Factor-rating method is to determine several major factors from all the work to be evaluated; score each factor according to the standard and determine the corresponding level based on the total scores.

d) Analytic hierarchy process

Logistics network layout problems are not only optimization of minimizing transportation cost. It involves many levels, such as economy, society, environment, shipping channel network, which requires comprehensive analysis and evaluation. When several alternatives are selected, analytic hierarchy process can be used to select the optimal solution.

\section{3) Multipoint logistics center location}

\section{a) single product location method}

Theory of single product location mainly solves problem by selecting a number of locations from a set of candidate locations as the logistics facility network (e.g., distribution center), minimizing the total logistics distribution cost or transportation costs and maximizing the efficiency of logistics operation when carrying the same product to a number of customers from a number of known resources (e.g., factories) going by the facility network (distribution center).

\section{b) Multi-product location method}

Selecting a number of locations from a set of candidate locations as the logistics facility network (e.g., distribution center, warehouse, etc), minimizing the total transportation cost and maximizing the efficiency of logistics operation when carrying the multi-product to a number of customers from a number of known resources (e.g., factories) going by the facility network (distribution center, warehouse, etc.).

\section{Affecting factors of logistics distribution center location}

There are many factors affecting logistics center location decisions, which can be summarized in three aspects as enterprise internal factors, external environmental factors and logistics cost factors.

\section{1) Enterprise internal factors}

Enterprise internal factors include two aspects of corporate strategy and product technology. The influence of enterprise internal factors mainly reflects that the enterprise competition strategy has important effect on logistics network design. Production cost oriented enterprises tend to layout production facilities at the region with lowest cost, in order to reduce the enterprises production cost.

2) The diversification of transportation mode and the development of transportation

Single transport may not need the goods in the conversion between the means of transport, when various transport, such as the planes, trains, automobiles, ships and various means of transport integrate together, the goods in the conversion between the transport makes logistics business increasingly complex.

\section{3) Factors of the development of road traffic}

The development of highway greatly shortens the duration of the goods transport; more and more choose road when transportation within 1000 kilometers. The United States built the national highway system in 1930s, which changed the logistics nodes or the logistics center layout. Many small warehouses disappeared, replaced by logistics center distributed in transport hub and edge of city with advanced equipment and high turnover rate.

4) Factors of reducing logistics cost

Competition and the pursuit of high profits force firms to reduce their logistics costs. When the market competition pressure is not enough, manufacturers, warehouses and owners of transportation are relatively independent of each other, however, with the gradual increase of pressure from market competition, the three discover that they must closely cooperate to reduce logistics cost.

\section{LOGISTICS DISTRIBUTION CENTER LOCATION BASED ON GRAVITY METHOD}

There are lots of ways for logistics distribution center location research, but still need to be supported by scientific modeling and quantification method, which can be roughly divided into two major categories of qualitative and quantitative. Qualitative method is mainly to combine analytic hierarchy process and fuzzy comprehensive evaluation for index evaluation of various schemes, and find out the optimal address; quantitative method is mainly divided into two categories of continuous model and discrete model. The representative of continuous model is gravity method.

\section{A. Basic concept of the centre-of-gravity method}

The centre-of-gravity method is a method of setting a single workshop or warehouse; the main consideration of this method is the distance between the existing facilities and traffic volume of goods, which are often used in the 
selection of intermediate warehouse or distribution warehouse.

The center-of-gravity method is a kind of simulation method. This approach treats demand point and resource point in the logistics system as the logistics system distributed within the scope of a plane. The demand and resource of each point is respectively regarded as the weight of the object. The center of gravity of object system is regarded as the optimum set point of logistics node, determining the position of the logistics network by finding the center of gravity of the object system.

The center-of-gravity method is generally applied to unitary network layout. Unitary network distribution refers to the problem of setting the only logistics network in the planned area. In the circulation field, multivariate network layout problems are more than the unitary network layout.

\section{B. Basic principle and step of center-of-gravity method}

\section{1) Assumption terms of center-of-gravity method}

The center-of-gravity method mainly solves the logistics network planning problems generated by the transport flow from a starting point to an end point. The decision-making basis of the center-of-gravity method is the product transportation cost minimization, which involves the following four assumption preconditions:

The demand of decision points is not the actual demand geographically, but an aggregation which brings together numerous demand scattered in some area.

The logistics costs of product distribution are expressed in the form of transportation costs, and transportation costs of product is only in direct proportion to the straight-line distance between distribution center and demand point, without considering the condition of city traffic.

Take no account of the cost difference caused by different geographical position of distribution center, such as land use fee, construction fee, labor cost, inventory cost, etc.

Take no account of the future benefits and cost variations of enterprise operation, and ensure a relatively static decision-making environment.

2) Concrete model of the center-of-gravity method

Determined by the above four assumptions, the only decision-making factors of center-of-gravity method is the transportation cost in the process of product distribution, as long as the location of distribution center to minimize transportation costs is reasonable and optimal.

Assuming that the new distribution center is $\mathrm{P}$; corresponding position coordinates is $\mathrm{P}(\mathrm{a}, \mathrm{b})$; demand point is $\mathrm{A}(\mathrm{Xi}, \mathrm{Yi}$ ) (of which $\mathrm{i}=1,2,3 \ldots \ldots \mathrm{n}$ ); the distance between distribution center $\mathrm{P}$ and demand point $\mathrm{A} d(\mathrm{~A}, \mathrm{P})$ is as follows:

$$
d(A, P)=k \sqrt{(X i-a)^{2}+(Y i-b)^{2}}
$$

(Of which, $\mathrm{k}$ is a

proportionality coefficient)

In the distribution chain, if the product needs to be transported between distribution center $\mathrm{P}$ and $\mathrm{n}$ demand points (A1, A2, A3,..., An), and the traffic volume between them is $(\mathrm{W} 1, \mathrm{~W} 2, \mathrm{~W} 3, \ldots \ldots ., \mathrm{Wn})$ separately, given the transportation charges from distribution center $\mathrm{P}$ to demand point $: \mathrm{Ci}$, the total fee $\mathrm{H}$ :
$H=\sum_{i}^{n} C i \cdot W i \cdot d(A, P)=\sum_{i}^{n} C i \cdot W i \cdot k \sqrt{(X i-a)^{2}+(Y i-b)^{2}}$

Our final decision of distribution center location, the coordinate, should make the above equation $\mathrm{H}$ get the minimum and that is the unencumbered minimization problem in mathematics. In concrete terms, find the partial derivatives of the new distribution center; the other two partial derivatives function is zero, so the expression of a and $b$ is:

$$
\begin{aligned}
& a=\frac{\sum_{i}^{n} C_{i} \cdot W i \cdot X i / d}{\sum_{i}^{n} C i \cdot W i / d} \\
& b=\frac{\sum_{i}^{n} C_{i} \cdot W i \cdot Y i / d}{\sum_{i}^{n} C_{i} \cdot W_{i} / d}
\end{aligned}
$$

Of which: the value of $a, b$ is the coordinate of optional location facilities;

$\mathrm{Xi}, \mathrm{Yi}$ is the coordinate of given supply point and demand point.

\section{Solving steps of center-of-gravity method}

Step 1: find the given coordinate of supply point and demand point, the traffic volume and line transport rate

Step 2: ignore calculated value $d(A, P)$, make $d=1$, and work out the initial coordinates of optional location according to the formula (3) and formula (4).

$$
\begin{gathered}
\boldsymbol{a}_{\mathrm{o}}=\frac{\sum_{i}^{n} C i \cdot W i \cdot X i}{\sum_{i}^{n} C i \cdot W i} \\
\boldsymbol{b}_{\mathrm{o}}=\frac{\sum_{i}^{n} C i \cdot W i \cdot Y i}{\sum_{i}^{n} C i \cdot W i}
\end{gathered}
$$

Step 3: according to (a0, b0), work out d, and put aside the proportion coefficient $\mathrm{k}$;

Step 4: work out the correction of $(a, b)$ by substituting $\mathrm{d}$ into formula (3) and formula (4); d;

Step 5: according to the correction of $(a, b)$, recalculate

Step 6: repeat step 4 and 5 until the change of $(a, b)$ is less than the predetermined error range;

Step 7: calculate the total transportation cost according to the best coordinate values obtained.

\section{CONCLUSION}

In the logistics system, logistics center location is a strategic important issue in the optimization of logistics system. The importance of logistics center location as the nodes of logistics network stands in the breach. Because the modern logistics theory research in China is relatively lagging behind the need of logistics practice, most of logistics enterprises make assumed decisions only by experience in the logistics center location, or only paying attention to short-term benefits, which not only go against the long-term development of the enterprise, but also cause great waste of resources. In this paper, starting from the logistics center location, influence factors and the required data, this paper established a logistics center location model, and analyzed the priority of candidate location with 
analytic hierarchy process method combined with the examples.

Solving the above realistic problems is extremely helpful to resolve the problem of logistics distribution center location, improve the service quality of logistics system, reduce the operating costs of logistics system, and finally play a big role in promoting the progress and development of human society, which must be a long process of development.

\section{REFERENCES}

[1] Liu Zhenpeng, Discuss the logistics development of e-commerce [M]. Science \&Technology Information 2010(2):202 .

[2] Liu Yuna. Theory of enterprise logistics management pattern under new e-commerce [J], Modern Business Trade Industry 2009 ( 1 ) : 346-347.

[3] Wang Changqiong. Logistics system engineering [M]. Beijing: China Material Press, 2009.

[4] Jiang Zhongyi. Problems of network location empowerment center and center-of-gravity[J]. Journal of Shenyang Normal University 2005,15-18

[5] Yu Hong. Research of distribution center location based on supply chain[D]. Jilin University, 2007.

[6] Wang Jiaju. Research and application of distribution center location based on center-of-gravity method [J]. Journal of Yangtze University, 2008,36-39.

[7] Zhang Tao. Research of logistics center location based on analytic hierarchy process [D]. Wuhan University of Science and Technology, 2008.

[8] http://wiki.mbalib.com/wiki/Centre_of_Gravity_Method.

[9] http://baike.baidu.com/view/857353.htm. 